\title{
Behavioral and Endocrine Responses of Rats With Hereditary Hypothalamic Diabetes Insipidus (Brattleboro Strain)
}

\author{
B. BOHUS, TJ.B. VAN WIMERSMA GREIDANUS AND D. DE WIED \\ Rudolf Magnus Institute for Pharmacology, Medical Faculty, University of Utrecht \\ Vondellaan 6, Utrecht, The Netherlands
}

(Received 15 November 1974)

\begin{abstract}
BOHUS, B., Tj. B. VAN WIMERSMA GREIDANUS AND D. DE WIED. Behavioral and endocrine responses of rats with hereditary hypothalamic diabetes insipidus (Brattleboro strain). PHYSIOL. BEHAV. 14(5) 609-615, 1975. - Behavioral and endocrine profiles were established of homozygous (HO-DI) and heterozygous (HE-DI) rats with hereditary hypothalamic diabetes insipidus in comparison to Wistar strain rats. HO-DI rats were inferior in acquiring and maintaining active and passive avoidance behavior. Behavioral deficits were most obvious in a step-through one-trial learning passive avoidance test and least in multiple trial one way active avoidance test. Plasma corticosterone levels determined after the retention test appeared to be closely related to the passive avoidance behavior of the HO-DI rats. Passive avoidance immediately after the single learning trial was associated with elevated plasma corticosterone level; absence of avoidance and absence in plasma corticosterone elevation was observed $24 \mathrm{hr}$ after learning. These observations are compatible with the hypothesis that vasopressin is involved in the consolidation and/or retrieval of learned responses. Differences between HO-DI and Wistar rats in open field behavior, in response threshold to electric footshock, and in a number of somatic endocrine parameters are reported and discussed.
\end{abstract}

Hereditary hypothalamic diabetes insipidus Vasopressin Shuttle box avoidance Pole jumping avoidance Step-through passive avoidance Plasma corticosterone response Open field Footshock responsiveness Body growth Hypophysis Adrenal Testis

\begin{abstract}
VASOPRESSIN or antidiuretic hormone (ADH) of posterior pituitary origin plays an important role in the organization of adaptive behavior. Removal of the posterior lobe of the pituitary gland interferes with the maintenance of a shuttle box avoidance response in the rat which can be restored by treatment with pitressin or lysine-8-vasopressin (LVP) [21]. Impaired acquisition of a similar avoidance response which occurs after hypophysectomy is ameliorated by LVP [6]. In the intact rat the same preparations increase resistance to extinction of both a shuttle box and pole jumping avoidance response [23, 24, 29] and facilitate passive avoidance behavior $[2,5]$. These behavioral effects of vasopressin are of a long term nature and last much longer than can be accounted for by the actual presence of the peptide in the organism $[6,23,24]$. The effect of vasopressin on behavior is not due to its classical endocrine activities. Desglycinamide-8-lysine vasopressin (DG-LVP), a peptide isolated from hog pituitary material which lacks almost all antidiuretic and pressor activities [26], also stimulates avoidance acquisition in hypophysectomized rats [8], increases resistance to extinction of a pole jumping avoidance response [26], and improves passive avoidance retention in the intact rat [15]. These
\end{abstract}

observations together with those showing similar behavioral effects of intracerebrally and peripherally administered LVP [29] led to the hypothesis that vasopressin acts in the central nervous system probably on memory processes.

These studies, however, did not allow a conclusion as to whether endogenous vasopressin, which release is stimulated during the behavioral performance of the rat in a passive avo1dance situation [15] is physiologically involved in memory processes. The availability of rats with hereditary hypothalamic diabetes insipidus (DI) provided a model to study memory function in the absence of vasopressin. Homozygous hereditary diabetes insipidus rats of the Brattleboro strain (HO-DI) lack the ability to synthetize vasopressin while the1r heterozygous litter mates (HE-DI) have a relatively normal water metabolism [16,18]. A previous study had revealed a memory deficit in HO-DI rats subjected to a one-trial passive avoidance test which could be restored by the subcutaneous injection of arginine-8vasopressin (AVP) or DG-LVP when given immediately after the learning trial [25]. It might be possible however that multiple learning trials would elicit memory formation in HO-DI rats, indicating that the memory deficit is not of an absolute nature. The present experiments were designed 
to establish a behavioral profile of the HO-DI rat as compared to its heterozygous litter mate (HE-DI) using active and passive avoidance test procedures. In addition, pituitary-adrenal activity was monitored in rats subjected to passive avoidance behavior in order to investigate the endocrine consequences of the memory deficit which has been observed in diabetes insipidus rats [25].

\section{METHOD}

\section{Antmals}

Male Long Evans SPF HO-DI and HE-DI rats (Brattleboro strain) were obtained from Central Breeding Laboratories TNO (Ze1st, The Netherlands). They weighed approximately $90 \mathrm{~g}$ upon arrival. Male Wistar rats which originated from the same breeding laboratories but bred by us, weighed also around $90 \mathrm{~g}$ at the onset of experiments. The rats were housed under ad lib food and water conditions and the light was on from 5 a.m. to 7 p.m. in the animal colony. All observations were made between 11 a.m. and 3 p.m.

\section{Procedure}

Brattleboro rats were differentiated for homozygous and heterozygous diabetes insipidus by measuring $24 \mathrm{hr}$ water intake during 2 consecutive days in metabolic cages. For comparison the water intake of Wistar rats was also determined. The water intake amounted to $76.6 \pm 3.6$ in HO-DI rats, $13.0 \pm 1.0$ in $\mathrm{HE}-\mathrm{DI}$ and $17.6 \pm 3.8 \mathrm{ml} / 100 \mathrm{~g}$ body we1ght in Wistar rats.

To determine weights of several endocrine organs, rats were decaptitated at the end of an experiment and adrenals, testes and pituitary lobes removed, dissected clean and weighed to the nearest $0.1 \mathrm{mg}$.

Behavioral techniques. Active avoidance behavior was studied in a shuttle box or a pole jumping situation. In the shuttle box acquisition and extinction of the conditioned avoidance response was studied with $12 \mathrm{HO}-\mathrm{DI}, 11 \mathrm{HE}-\mathrm{DI}$ and 10 Wistar rats. Rats weighed $120-130 \mathrm{~g}$ at the onset of conditioning. The procedure has been described in detall elsewhere [20]. Briefly; the rats were trained to avoid the unconditioned stimulus (US) of an electric footshock $(0.16$ $\mathrm{mA}, \mathrm{AC}$ ) delivered through the grid floor by crossing a barrier between identical compartments to the non-electrified compartment of the shuttle box. The conditioned stımulus (CS) was a buzzer which was presented for $5 \mathrm{sec}$ prior to the US. Ten conditioning trials were given daily for 12 days. The average intertrial interval was $60 \mathrm{sec}$ varying between 40 and $80 \mathrm{sec}$. Acquisition training was followed by 7 extinction sessions. Ten non-reinforced trails were presented in each session.

Acquisition and extinction of a pole jumping avoidance response were studied on $10 \mathrm{HO}-\mathrm{DI}, 9 \mathrm{HE}-\mathrm{DI}$ and $7 \mathrm{Wistar}$ rats weighing $110-120 \mathrm{~g}$ at the onset of the training. The rats were conditioned to avoid the US of an electric floor shock $(0.20 \mathrm{~mA}, \mathrm{AC})$ by jumping onto a pole located in the center of the conditioning apparatus [22]. The CS was a light signal which was presented for $5 \mathrm{sec}$. The US was applied if an avoidance response had not occurred within 5 sec of CS presentation. Ten acquisition trials were given daily for 6 days with intertrial intervals averaging $60 \mathrm{sec}$. Ten non-reinforced extinction trials per day were presented on the next 4 successive days.

Passive avoldance behavior was studied in a simple step- through type of passive avoidance situation as described in detail elsewhere [1]. Briefly, rats were adapted to the apparatus consistıng of a large dark compartment equipped with a grid floor and a mesh-covered elevated runway attached to the front center of the dark chamber. Adaptation training was followed by a single trial in which the rat was placed on the elevated platform and allowed to enter the dark box. Three such trials were given on the next day with an intertrial interval of $5 \mathrm{~min}$. After the third trial the rat received a single $3-\mathrm{sec}$ unavoidanble scrambled footshock $(1.0 \mathrm{~mA}, \mathrm{AC})$ immediately after entering the dark compartment. Retention of the response was tested $1 \mathrm{~min}$, 3 or $24 \mathrm{hr}$ after the shock trial. The rat was placed on the elevated runway and the latency to re-enter the shock compartment was recorded to a maximum of $300 \mathrm{sec}$. Rats trained and tested in the same way without recelving shock served as controls. A total of $48 \mathrm{HO}-\mathrm{DI}$ and $51 \mathrm{HE}-\mathrm{DI}$ rats were used in these experiments.

Open field behavior of homozygous and heterozygous DI and Wistar rats was studied in a circular open field arena as described by Weijnen and Slangen [19]. Ambulation (number of floor units entered), rearıng, grooming and defecation scores were recorded during 3 -min sessions on 4 consecutive days.

Responsiveness to electric footshock was determined on HO-DI, HE-DI and Wistar rats. Response to footshock was studied by using two sets of 12 shock intensities varying between 33 and $300 \mu \mathrm{A}$ [7]. Behavioral responses recorded at each shock intensity were flinch and jerk, jump and run. The lowest intensity of shock eliciting these responses was used as the index of threshold responsiveness.

Measurement of pituitary-adrenal responsiveness. The rats which were subjected to passive avoldance training and tested for the retention of the response at one of the intervals as described in the foregoing paragraph, were returned to their home cage ( 2 or 3 rats per cage) at the end of the retention test. Fifteen min after the beginning of the retention test they were decapitated and blood was collected.

Pituitary-adrenal responsiveness of homozygous and heterozygous DI and Wistar rats was also determined after subjecting the animals to a shock responsiveness test. The rats were decapitated $8 \mathrm{~min}$ after the onset of the test.

By decapitation, trunk blood was collected in heparinized tubes, centrifuged and kept frozen until determination. Plasma corticosterone levels were determined on the basis of competitive protein binding assay [13]. Corticosterone was extracted from $20-50 \mu 1$ plasma samples with dichloromethane. In order to obtain transcortin, the binding protein plasma was collected from female rats 3 days after adrenalectomy. The plasma dilution used was $1: 1000 .{ }^{3} \mathrm{H}-1,2$-corticosterone in a concentration of approximately $25000 \mathrm{dpm}$ was then added to each $\mathrm{ml}$ of transcortin preparation. The preparation was incubated for $5 \mathrm{~min}$ and added to the plasma extracts or to reference corticosterone standards. These mixtures were again incubated for $5 \mathrm{~min}$ at $45^{\circ} \mathrm{C}$. In order to separate bound and free corticosterone, dextrane coated charcoal was added to the samples at the end of incubation. The radioactivity of upper, bound layer after centrifugation was determined by a liquid scintillation counter

\section{RESULTS}

Shuttle box avordance behavior of HO-DI, HE-DI and 
Wistar rats is depicted in Fig. 1. Although all HO-DI rats acquired the shuttle box response as indicated by an approximately 80 percent performance level at the end of the 12-day acquisition period, the rate of acquisition was slower in these animals than in both HE-DI and Wistar rats. The total number of avoidance responses scored by the HO-DI rats $(82.6 \pm 5.3)$ was significantly $(p<0.01, t$-test $)$ lower than those observed in both the HE-DI $(102.9 \pm 2.4)$ and the Wistar rats $(101.8 \pm 3.0)$. No differences were observed in acquisition of the shuttle box response by HEDI and Wistar rats. Rapid extinction of the conditioned avoldance took place in the HO-DI rats. HE-DI rats showed a slower rate of extinction than HO-DI rats. The number of avoidance responses scored by the HE-DI rats $(34.0 \pm 4.9)$ was significantly higher $(p<0.05)$ than in HO-DI rats $(21.0$ \pm 3.3 ). However, despite a similar acquisition behavior, HEDI rats showed less retention of the avoidance response during the extinction training than Wistar rats. The latter group was significantly $(p<0.01)$ superior in avoidance retention (56.0 \pm 2.4 avoidance responses) than HO-DI or HE-DI rats.

The rate of acquisition of the pole jumping response appeared to be the same in HO-DI and HE-DI rats (Fig. 2). Both groups reached an approximately 75 percent performance level at the end of the 6-day acquisition training. However, Wistar rats acquired the response much more rapidly. The number of conditioned avoidance responses scored during the acquisition period $(41.0 \pm 0.7)$ appeared to be significantly $(p<0.01)$ higher than in both HO-DI $(29.1 \pm 1.8)$ and HE-DI $(30.0 \pm 1.4)$ rats. Rapid decline in avoidance performance was observed in DI rats in the absence of reinforcement. Analysis of the total number of avoidance responses revealed a more superior $(p<0.01)$ avoidance retention of Wistar rats $(27.0 \pm 0.6)$ than of the HE-DI animals $(21.0 \pm 1.0)$. Although with a seemingly marginal difference, HE-DI rats performed the avoidance response better than HO-DI rats durng the extinction period $(p<0.01)$. The latter group scored $16.2 \pm 1.0$ avoidance responses.

Results on passive avoidance behavior are summarized in Table 1. Retention of the passive avoidance response as indicated by the median latencies to re-enter the shock compartment was in the same order of magnitude in HOand HE-DI rats at the immediate $(0 \mathrm{hr})$ retention trial. Both groups showed full passive avoidance behavior $1 \mathrm{~min}$ after the learning trial. However, HO-DI rats displayed partial passive avoldance at $3 \mathrm{hr}$ and none at $24 \mathrm{hr}$ after the learning trial, while HE-DI rats showed full avoidance behavior.

The same rats as used in the experiments described in the foregoing paragraph were used to determine the pituitary-adrenal response as measured during retention tests in the passive avoidance situation. Plasma corticosterone levels were measured $15 \mathrm{~min}$ after the onset of the retention tests. Increase in plasma corticosterone in shocked rats as compared to non-shocked controls was of the same order of magnitude in both DI groups $15 \mathrm{~min}$ after the 0 -hr retention trial. When compared to non-shocked controls HO-DI rats which had received shock had higher plasma corticosterone $15 \mathrm{~min}$ after the $3 \mathrm{hr}$ retention test. However, significantly lower levels were observed in HO-DI than HE-DI rats $(p<0.001)$. The HO-DI animals failed to respond with an increase in plasma corticosterone at the 24 $\mathrm{hr}$ retention test.

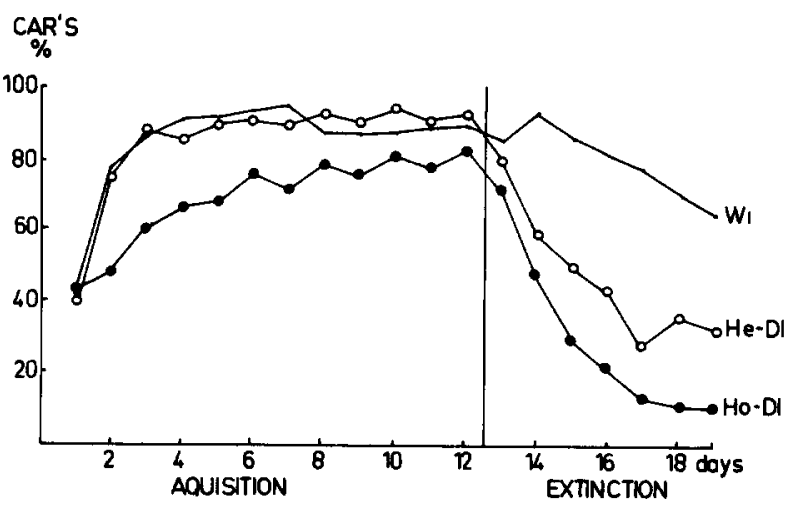

FIG. 1. Acquisition and extinction of a shuttle box avoidance response in homozygous (HO-DI) and heterozygous (HE-DI) diabetes insipidus rats and in Wistar (Wi) rats.

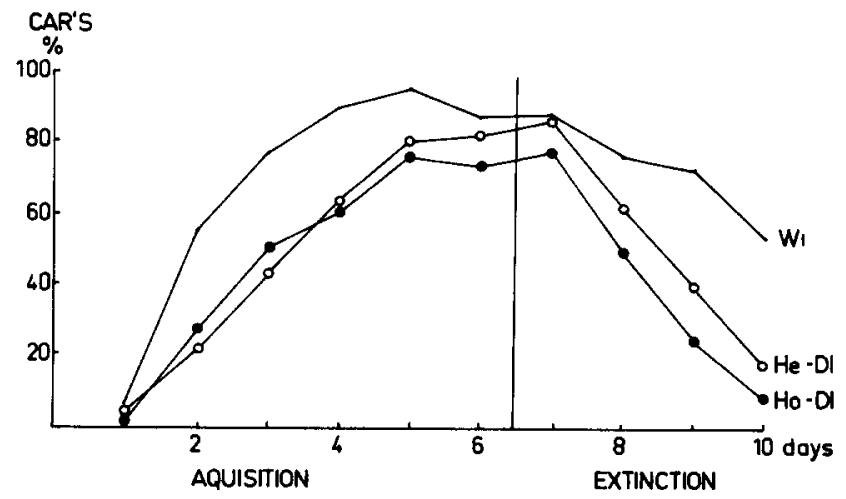

FIG. 2. Acquisition and extinction of a conditioned avoidance response in a pole jumping situation in homozygous (HO-DI) and heterozygous (HE-DI) diabetes insipidus rats and in Wistar (Wi) rats.

Almost no differences in the open field behavior of HODI and HE-DI rats were apparent (Table 2). Ambulation activity, rearing both around the wall and in the middle of the arena remained constantly high during the 4 sessions. Wistar rats, however, behaved differently in this situation. Ambulation and rearing around the wall activities gradually decreased, resulting in significantly lower scores during especially the last session when compared to the Brattleboro rats. Rearing in the middle of the arena was also less frequent in the Wistar rats but mainly during the first session. Grooming activity was almost in the same order of magnitude as in DI rats. The defecation score as indicated by the number of boluses, on the other hand, appeared to be significantly higher in Wistar rats but only during the first session.

The threshold currents to elicit flinch or jerk, jump and run responses were in the same order of magnitude in HOand HE-DI rats (Table 3). However, less current was necessary to evoke jerk, jump and run responses in Wistar rats. Pituitary-adrenal activity as indicated by the plasma corticosterone levels after the presentation of shock series were not different between HO-DI and HE-DI or HO-DI and Wistar rats. HE-DI rats responded, however, with larger increase in plasma corticosterone than Wistar rats. 
TABLE 1

PITUITARY-ADRENAL RESPONSE DURING RETENTION OF PASSIVE AVOIDANCE LEARNING IN HOMOZYGOUS AND HETEROZYGOUS DIABETES INSIPIDUS (DI) RATS

\begin{tabular}{|c|c|c|c|c|c|c|c|c|c|c|}
\hline \multirow{4}{*}{ Strain } & \multirow{2}{*}{\multicolumn{7}{|c|}{$\begin{array}{l}\text { Passive Avoidance Behavior } \\
\text { Passive Avoidance Latency* } \\
\text { Retention Test }\end{array}$}} & \multirow{2}{*}{\multicolumn{3}{|c|}{$\begin{array}{l}\text { Pituitary-Adrenal Response } \\
\text { Plasma Corticosterone Level } \dagger \\
\text { Retention Test }\end{array}$}} \\
\hline & & & & & & & & & & \\
\hline & \multirow{2}{*}{$\begin{array}{c}\begin{array}{l}\text { Intensity } \\
\mathrm{mA} / 3 \mathrm{sec}\end{array} \\
1.0\end{array}$} & \multicolumn{2}{|c|}{$0 \mathrm{Hr}$} & \multicolumn{2}{|c|}{$3 \mathrm{Hr}$} & \multicolumn{2}{|c|}{$24 \mathrm{Hr}$} & \multirow{2}{*}{$\frac{0 \mathrm{Hr}}{26.4 \pm 2.5^{\mathrm{a}}}$} & \multirow{2}{*}{$\frac{3 \mathrm{Hr}}{13.6 \pm 1.8 \ddagger}$} & \multirow{2}{*}{$\frac{24 \mathrm{Hr}}{124 \pm 1.6}$} \\
\hline & & $287.5 \S$ & (8) & $25.5 \S$ & (8) & 15.0 & $(10)$ & & & \\
\hline & 0.0 & 9.5 & (6) & 10.0 & (6) & 9.5 & (10) & $9.4 \pm 0.6$ & $8.6 \pm 06$ & $10.5 \pm 1.9$ \\
\hline \multirow[t]{2}{*}{ HE-DI } & 1.0 & $300.0 \S$ & (8) & $300.0 \S$ & (8) & $300.0 \S$ & $(10)$ & $24.9 \pm 1.3^{\mathrm{a}}$ & $24.2 \pm 1.0^{\mathrm{a}}$ & $23.4 \pm 1.8^{\mathrm{a}}$ \\
\hline & 0.0 & 9.5 & (8) & 10.5 & (8) & 60 & (9) & $8.6 \pm 0.5$ & $8.3 \pm 06$ & $12.2 \pm 1.9$ \\
\hline
\end{tabular}

Behavioral data were analysed by U-test and plasma cortıcosterone by $t$-test; number of rats in parentheses

*Median in sec

$\dagger$ Mean \pm S.E. in $\mu \mathrm{g} / 100 \mathrm{ml}$ plasma

$\ddagger p<0.05$

$\S p<0.01$

${ }^{\mathrm{a} p} p<0.001$

TABLE 2

OPEN FIELD BEHAVIOR OF HOMOZYGOUS (HO) AND HETEROZYGOUS (HE) DIABETES INSIPIDUS (DI) AND WISTAR RATS

\begin{tabular}{|c|c|c|c|c|c|}
\hline \multirow{3}{*}{$\begin{array}{l}\text { Open Field Behavior } \\
\text { Ambulation }\end{array}$} & \multirow{3}{*}{$\frac{\text { Session }}{1}$} & \multicolumn{4}{|c|}{ Strain } \\
\hline & & HO-DI & HE-DI & \multicolumn{2}{|l|}{ Wistar } \\
\hline & & $34.1 \pm 4.3 \dagger(6) \ddagger$ & $41.5 \pm 5.2$ & $48.8 \pm 3.6$ & (5) \\
\hline & 2 & $43.1 \pm 6.6$ & $40.9 \pm 6.4$ & $38.8 \pm 9.9$ & \\
\hline & 3 & $36.6 \pm 8.3^{*}$ & $47.6 \pm 4.4^{*}$ & $17.2 \pm 3.6$ & \\
\hline & 4 & $27.5 \pm 5.8^{*}$ & $33.6 \pm 6.7^{*}$ & $12.6 \pm 4.6$ & \\
\hline \multirow{4}{*}{$\begin{array}{l}\text { Rearing (in the } \\
\text { middle of the arena) }\end{array}$} & 1 & $14.0 \pm 3.0^{*}$ & $13.0 \pm 2.6^{*}$ & $6.8 \pm 1.7$ & \\
\hline & 2 & $4.8 \pm 23$ & $2.9 \pm 0.7$ & $1.2 \pm 0.6$ & \\
\hline & 3 & $1.8 \pm 1.0$ & $2.9 \pm 1.3$ & $0.6 \pm 0.4$ & \\
\hline & 4 & $0.8 \pm 0.4$ & $4.0 \pm 2.2$ & $0.2 \pm 0.2$ & \\
\hline \multirow{4}{*}{$\begin{array}{l}\text { Rearing (around the } \\
\text { wall of the arena) }\end{array}$} & 1 & $13.3 \pm 4.1$ & $14.7 \pm 3.5$ & $10.0 \pm 1.4$ & \\
\hline & 2 & $16.3 \pm 4.2^{*}$ & $9.1 \pm 27$ & $3.6 \pm 13$ & \\
\hline & 3 & $9.2 \pm 3.0^{*}$ & $12.8 \pm 2.1^{*}$ & $0.6 \pm 0.4$ & \\
\hline & 4 & $7.0 \pm 3.6$ & $8.2 \pm 2.1^{*}$ & $08 \pm 0.6$ & \\
\hline \multirow[t]{4}{*}{ Grooming } & 1 & $1.3 \pm 0.4$ & $1.4 \pm 04$ & $16 \pm 0.6$ & \\
\hline & 2 & $1.3 \pm 0.4$ & $1.9 \pm 0.5$ & $1.8 \pm 0.6$ & \\
\hline & 3 & $1.0 \pm 0.6$ & $1.9 \pm 0.5^{*}$ & $0.4 \pm 0.2$ & \\
\hline & 4 & $1.7 \pm 0.4^{*}$ & $1.7 \pm 0.7$ & $0.6 \pm 0.4$ & \\
\hline \multirow[t]{4}{*}{ Number of boluses } & 1 & $1.5 \pm 0.7^{*}$ & $1.6 \pm 0.4 *$ & $3.0 \pm 0.4$ & \\
\hline & 2 & $1.7 \pm 1.1$ & $1.9 \pm 0.4$ & $2.4 \pm 0.9$ & \\
\hline & 3 & $0.5 \pm 0.3$ & $2.1 \pm 0.5$ & $1.4 \pm 0.6$ & \\
\hline & 4 & $26 \pm 1.0$ & $1.0 \pm 0.4$ & $2.0 \pm 0.6$ & \\
\hline
\end{tabular}

*Significantly different from Wistar rats, $p<005$

$\dagger$ Mean \pm S.E.

$\$$ Number of rats 
TABLE 3

BEHAVIORAL RESPONSE THRESHOLD VALUES AND PITUITARY-ADRENAL SYSTEM RESPONSE TO ELECTRIC SHOCK IN HOMOZYGOUS AND HETEROZYGOUS DIABETES INSIPIDUS (DI) AND WISTAR RATS

\begin{tabular}{lcccc}
\hline \multicolumn{1}{c}{ Strain } & $\begin{array}{c}\text { No. } \\
\text { of Rats }\end{array}$ & $\begin{array}{c}\text { Flinch } \\
(\mu \mathrm{A})\end{array}$ & $\begin{array}{c}\text { Jerk, Jump and Run } \\
(\mu \mathrm{A})\end{array}$ & $\begin{array}{c}\text { Plasma Corticosterone Level } \\
(\mu \mathrm{g} / 100 \mathrm{ml} \text { Plasma })\end{array}$ \\
\hline Homozygous DI & 9 & $83.1 \pm 6.3^{*} \dagger$ & $146.2 \pm 1.0 \ddagger$ & $22.1 \pm 5.6$ \\
Heterozygous DI & 9 & $77.1 \pm 3.9$ & $131.8 \pm 5.1 \ddagger$ & $27.7 \pm 1.5 \ddagger$ \\
Wistar & 9 & $66.4 \pm 4.9$ & $97.1 \pm 4.9$ & $15.3 \pm 2.1$ \\
\hline
\end{tabular}

\footnotetext{
${ }^{*}$ Mean \pm S.E.

$\dagger p<0.05$ (DI versus Wistar rats) $\underset{+\neq}{+}<<0.01$
}

TABLE 4

BODY GROWTH AND ENDOCRINE ORGAN WEIGHTS IN HOMOZYGOUS AND HETEROZYGOUS DIABETES INSIPIDUS (DI) AND WISTAR RATS

\begin{tabular}{lrrr}
\hline Body Weight (g) & Homozygous DI $(7)$ & Heterozygous DI $(6)$ & Wistar (6) \\
\hline Day 1 & $89.10 \pm 4.10^{*}$ & $95.60 \pm 4.60$ & $94.00 \pm 2.40$ \\
Day 7 & $119.70 \pm 4.50^{\mathrm{a}}$ & $127.50 \pm 4.50$ & $129.20 \pm 3.60$ \\
Day 14 & $147.50 \pm 4.20^{\mathrm{a}}$ & $174.00 \pm 3.00$ & $175.80 \pm 3.30$ \\
Day 21 & $184.10 \pm 6.00^{\mathrm{a}}$ & $222.00 \pm 2.00$ & $220.10 \pm 4.20$ \\
Day 28 & $223.60 \pm 7.30 \S$ & $265.00 \pm 9.70$ & $272.30 \pm 4.50$ \\
Anterior pituitary $\dagger$ & $2.60 \pm 0.30$ & $2.38 \pm 0.25$ & $2.29 \pm 0.34$ \\
Posterior pituitary & $1.02 \pm 0.05 \ddagger$ & $0.52 \pm 0.02$ & $0.48 \pm 0.01$ \\
Adrenal & $11.60 \pm 0.33$ & $10.63 \pm 0.69^{\mathrm{b}}$ & $14.88 \pm 0.60$ \\
Test1s & $758.90 \pm 40.30$ & $656.60 \pm 57.10^{\mathrm{b}}$ & $1056.50 \pm 40.30$ \\
\hline
\end{tabular}

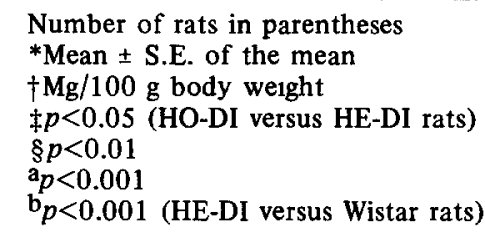

Body weight gain of HO-DI rats as studied in the rats subjected to shuttle box avoidance training was markedly retarded when compared to both HE-DI and Wistar rats. Although weights were similar at the start of the experiment, body weight of HO-DI rats remained significantly below those of HE-DI and Wistar rats (Table 4).

The weight of a number of endocrine organs was also determined in the same groups of rats at the end of the experiment in the shuttle box. Brattleboro rats, whether or not homo- or heterozygous, had smaller adrenals and testicles than the Wistar rats. Anterior pituitary weights were in the same order of magnitude while HO-DI rats had significantly heavier posterior pituitaries than either HE-DI or Wistar rats (Table 4).

\section{DISCUSSION}

The main findings of these experiments support the hypothesis that vasopressin is physiologically involved in memory processes. Acquisition of a shuttle box avoidance response, extinction behavior in both a shuttle box and a pole jumping avoidance situation and retention of a passive avoidance response appeared to be impaired in homozygous DI rats as compared to their heterozygous litter mates or normal Wistar rats. The difference between homozygous and heterozygous rats is a genetical deficit in the ability to synthetize vasopressin in HO-DI rats $[17,18]$.

In a previous study it was found that memory function of HO-DI rats is completely impaired in a one-trial learning passive avoidance situation when retention is tested $24 \mathrm{hr}$ or later after the shock trial [25]. Administration of arginine vasopressin (AVP) immediately after the learning trial restores passive avoidance behavior of HO-DI rats. This favours the hypothesis that memory rather than learning processes are disturbed in the absence of vasopressin. Indeed, the present data show that homozygous DI rats are 
able to acquire fear-motivated responses. Thus, acquisition of the pole jumping avoldance response appeared to be the same in HO-DI and HE-DI rats. Although the rate of acquisition was slower, HO-DI rats displayed avoidance behavior in the shuttle box as well. Furthermore, full retention of the passive avoidance response was observed in HO-DI rats when retention was tested shortly after the learning trial. Taken together, these observations indicate that learning may take place in the absence of vasopressin. Extinction of active avoidance behavior was facilitated in HO-DI rats. Furthermore, retention of the passive avoldance response at $3 \mathrm{hr}$ after the learning trial was very partial and completely absent at the $24 \mathrm{hr}$ retention test. These observations suggest that consolidation of memory is impaired in the absence of vasopressin. This may result in a deficit in preserving the acquired responses of both active and passive avordance behavior. DG-LVP was found to reduce $\mathrm{CO}_{2}$-induced amnesia for a passive avoidance response when administered prior to the single acquisition trial [14]. This also suggests that vasopressin analogues are involved in memory consolidation. However, the possibility that these peptides influence retrieval cannot be excluded. DG-LVP had an anti-amnesic effect as well when injected prior to the retention trial [14]. Furthermore, vasopressin release is increased during the retention test of a passive avoidance response and the rate of increase is related to the avoidance latency of the rat [15]. It might be that an association between endogenous release of vasopressin and specific environmental cues is of physiological significance in the maintenance of new behavior patterns [5].

The above mentioned considerations are based mainly upon comparisons between the behavior of homozygous DI rats and that of their heterozygous litter mates. The fact that open field activity and responsiveness to footshock were almost the same in HO- and HE-DI rats excludes the possibility that differences in avoidance behavior were due to different exploratory or motor activity and sensitivity to a painful stimulus. The behavior of HE-DI rats, however, was not always comparable to that of the Wistar rats. Thus, HE-DI rats are slower in acquiring the pole jumping avoidance response and extinction of both the shuttle box and the pole jumping avoidance response appeared to be more rapid in these animals than in Wistar rats. The open field activity of DI rats showed no decline over the observation sessions and higher shock intensities were necessary to evoke at least jerk, jump and run response. The albino Wistar rat is not the best control for the HE-DI rats. Although the HE-DI rat, which originates from the pigmented Long Evans strain, is able to synthetize vasopressin, it has a partial deficit in the synthesis [17] and an impaired release in response to hydration or dehydration $[10,12]$. Thus, apart from a strain difference, the disturbance in vasopressin synthesis and release may also be responsible for the accelerated avoidance extinction in $\mathrm{HE}$ DI rats. The fact that posterior lobectomized Wistar rats acquire a shuttle box response similar to that of intact controls but are less resistant to extinction [21] is in keeping with this notion. The poster1or lobectomized rat is able to synthetize vasopressin but in the absence of the storage organ it has an impaired release of this peptide hormone [11].

The pituitary-adrenal responses of HO-DI rats as measured shortly after the passive avoldance retention test showed a marked relationship with the avordance behavior of these rats. At the immediate retention test when full passive avoidance behavior was obtained in HO-DI rats, an elevation of plasma corticosterone was observed of a similar magnitude as in HE-DI rats. At the $3 \mathrm{hr}$ retention test a partial avoidance behavior was associated with a reduced plasma corticosterone response, while retention imparment at $24 \mathrm{hr}$ was coupled with the absence of a significant increase in plasma corticosterone. These observations, therefore, indicate that the absence of vasopressin in homozygous rats which results in an imparment of a psychological mechanism also results in an impairment of endocrine response in an otherwise fear-provoking environment. Elevation of plasma corticosterone level as observed after the 1 mmediate retention test in the passive avoidance might be the result of both the pain caused by electric shocks given $1 \mathrm{~min}$ prior to the retention trial and the psychological stress effects of the procedure. HO-DI and HE-DI rats responded with a similar elevation of plasma corticosterone. Several authors have investigated the pituitary-adrenal function of HO-DI rats. Impairment of stress responses has been reported by McCann et al. [9], Yates et al [30] and Wiley et al [28], while normal functions were observed by Arimura et al. [3]. A reduced adrenal response to ACTH in HO-DI rats has also been found [28]. However, the present experıments suggest that impairment of the pituitary-adrenal response in HO-DI rats may primarily depend on a disturbance in the psychological response to stress. Plasma corticosterone level increase due to painful shock presentation was not different between HO- and HE-DI rats. In this respect it is worth mentioning that in the posterior lobectomized rat the pituitary-adrenal response to neurogenic (emotional) but not to systemic stress is disturbed [27].

The body growth of HO-DI rats appeared to be retarded as compared to that of their heterozygous litter mated. Similar findings have been reported by Valtin et al. [17]. According to Arimura et al [4], growth hormone content of the pituitary is lower in HO-DI rats but it is not clear whether synthesis or release of this hormone is affected It is possible therefore that a growth hormone deficit is the cause of the impaired memory of homozygous rats. This ought to be tested. However, AVP as well as desglycinamide lysine vasopressin (DG-LVP), a peptide devoid of the classical endocrine effects of vasopressin, both are able to restore memory function of HO-DI rats in the passive avoidance situation [25]. Vasopressin is effective in restoring deficient avoidance behavior in hypophysectomized rats $[6,8]$. This tends to rule out the possibility that the influence of vasopressin and analogues is through the release of growth hormone. Nor is it possible to interpret the results by assuming that the presence or absence of vasopressin involves pituitary ACTH release.

\section{REFERENCES}

1. Ader, R., J. A. W. M. Weijnen and P. Moleman. Retention of a passive avoidance response as a function of the intensity and duration of electric shock. Psychon. Scl. 26: 125-128, 1972.

2. Ader, R. and D. de Wied. Effects of lysine vasopressin on passive avoidance learning. Psychon. Sci. 29: 46-48, 1972.
3. Arımura, A., T. Saito, C Y. Bowers and A. V. Schally. Pituitary-adrenal activation in rats with hereditary hypothalamic diabetes insipıdus. Acta endocr. 54: 155-165, 1967. 
4. Arimura, A., S. Sawano, T. W. Redding and A. V. Schally. Studies on retarded growth of rats with hereditary hypothalamic diabetes insipidus. Neuroendocrinology 3: 187-192, 1968.

5. Bohus, B., R. Ader and D. de Wied. Effects of vasopressin on active and passive avoidance behavior. Hormones Behav. 3: $191-197,1972$.

6. Bohus, B., W. H. Gispen and D. de Wied. Effect of lysine vasopressin and $\mathrm{ACTH}_{4-10}$ on conditioned avoldance behavior of hypophysectomized rats. Neuroendocrinology 11: 137-143, 1973.

7. Gispen, W. H., TJ. B. van Wimersma Greidanus and D. de Wied. Effects of hypophysectomy and $\mathrm{ACTH}_{4}, 10$ on responsiveness to electric shock in rats. Physiol. Behav. 5: 143-146, 1970.

8. Lande, S., A. Witter and D. de Wed. Pituitary peptides. An octapeptide that stimulates conditioned avoidance acquisition in hypophysectomized rats. J. biol. Chem. 246: 2058-2062, 1971.

9. McCann, S. M., J. Antunes-Rodrigues, R. Nallar and H. Valtin. Pituitary-adrenal function in the absence of vasopressin. Endocrinology 79: 1058-1064, 1966.

10. Miller, M. and A. M. Moses. Radioimmunoassay of urinary antidiuretic hormone with application to study of the Brattleboro rat. Endocrinology 88: 1389-1396, 1971.

11. Moll, J. and D. de Wied. Observations on the hypothalamoposthypophyseal system of the posterior lobectomized rat. Gen. comp. Endocr. 2: 215-228, 1962.

12. Moses, A. M. and M. Miller. Accumulation and release of pituitary vasopressin in rats heterozygous for hypothalamic diabetes insipidus. Endocrinology 86: 34-41, 1970 .

13. Murphy, B. E. P. Some studies of the protein-binding of steroids and their application to the routine micro and ultramicro measurement of various steroids in body fluids by competitive protein-bunding radioassay. J. clin. endocr. Metab. 27: 973-990, 1967.

14. Rigter, H., H. van Riezen and D. de Wied. The effects of ACTH-and vasopressin-analogues on CO2-induced retrograde amnesia in rats. Physiol. Behav. 13: 381-388, 1974.

15. Thompson, E. A. and D. de Wied. The relationship between antidiuretic activity of rat eye plexus blood and passive avoidance behaviour. Physiol. Behav. 11: 377-380, 1973.

16. Valtin, H. Hereditary hypothalamic diabetes insipidus in rats (Brattleboro strain). A useful experimental model. Am. J. Med. 42: 814-827, 1967 .

17. Valtın, H., W. H. Sawyer and H. W. Sokol. Neurohypophysial principles in rats homozygous and heterozygous for hypothalarc diabetes insipidus (Brattleboro strain). Endocrinology 77: 701-706, 1965
18. Valtın, H. and H. A. Schroeder. Familial hypothalamic diabetes insipidus in rats (Brattleboro strain). Am. J. Physiol. 206: 425-430, 1964.

19. Weijnen, J. A. W. M. and J. L. Slangen. Effects of ACTHanalogues on extinction of conditioned behavior. In: Pituitary Adrenal and the Brain, Progress in Brain Research. Vol. 32 Edited by D. de Wied and J. A. W. M. Weijnen, Amsterdam: Elsevier Scientific Publishing Company, 1970, pp. 221-235.

20. Wied, D. de. Influence of anterior pituitary on avoidance learning and escape behavior. Am. J. Physiol. 207: 255-259, 1964.

21. Wied, D. de. The influence of the posterior and intermediate lobe of the pituitary and pituitary peptides on the maintenance of a conditioned avoidance response in rats. Int. J. Neuropharmac. 4: 157-167, 1965.

22. Wied, D. de. Inhibitory effect of ACTH and related peptides on extinction of conditioned avoidance behavior. Proc. Soc. exp. Biol. Med. 122: 28-32, 1966.

23. Wied, D. de. Long term effect of vasopressin on the maintenance of a conditioned avoidance response in rats. Nature 232: 58-60, 1971.

24. Wied, D. de and B. Bohus. Long term and short term effects on retention of a conditioned avoidance response in rats by treatment with long acting pitressin and $\alpha$-MSH. Nature 212: 1484-1486, 1966.

25. Wied, D. de, B. Bohus and TJ. B. van Wimersma Greidanus. Memory deficit in rats with hereditary diabetes insipidus. Brain Res. 85: 152-156, 1975.

26. Wied, D. de, H. M. Greven, S. Lande and A. Witter. Dissociation of the behavioural and endocrine effects of lysine vasopressin by tryptic digestion. Br. J. Pharmac. 45: 118-122, 1972.

27. Wied, D. de, P. G. Smelik, J. Moll and P. R. Bouman. On the mechanism of ACTH release. In: Major Problems in Neuro. endocrinology, edited by E. Bajusz and G. Jasmin. Basel/New York S. Karger, 1974, pp. 156-176.

28. Wiley, M. K., A. F. Pearlmutter and R. E. Miller. Decreased adrenal sensitivity to ACTH in the vasopressin-deficient (Brattleboro) rat. Neuroendocrinology 14: 257-270, 1974.

29. Wimersma Greidanus, Tj. B. van, B. Bohus and D. de Wied. Effects of peptide hormones on behaviour, In: Endocrinology, Proc. IVth Int. Congress Endocrinology, edited by R. O. Scow, Int. Congress Series No. 273. Amsterdam: Excerpta Medica Foundation, 1973, pp. 197-201.

30. Yates, F. E., S. M. Russel, M. F. Dalman, G. A. Hedge, S. M. McCann and A. P. S. Dhariwal. Potentration by vasopressin of corticotropin release by corticotropin-releasing factor. Endocrinology 88: 3-15, 1971. 